\title{
大型 LNG 外罐混凝土结构施工工艺技术提高与创新应用总结
}

\author{
Summary on the Improvement and Innovation of Construction Technology of \\ Large LNG Outer Tank Concrete Structure \\ 孙俊若
}

Junruo Sun

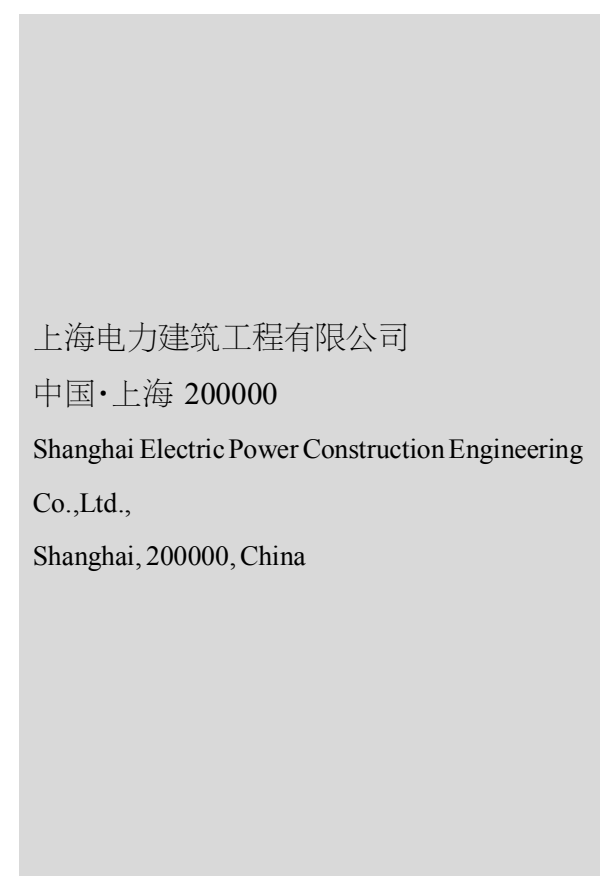

【摘要】LNG 储罐工程作为接收站主体核心组成部分, 不仅需要满足设计温度为零下 $165^{\circ} \mathrm{C}$ 左右低温常压存储环境条件要求, 而且在设计使用年限需满足罐内部低温不变生产 运行要求。一旦在运行期, 罐内部恢复常温时, 因罐体内部钢结构不具备二次低温条件可 逆性, 罐体将作报废处理。因此, 外罐低温预应力混凝土和内罐钢结构双包容大型 LNG 储 罐, 施工工艺技术要求之高, 不言而喻。

【Abstract】As the core part of the receiving station, LNG storage tank project not only needs to meet the requirements of low temperature and atmospheric pressure storage environment at the design temperature of $-165^{\circ} \mathrm{C}$, but also needs to meet the requirements of constant low temperature production and operation within the tank within the design service life. Once the tank is restored to normal temperature in the operation period, the tank will be scrapped because the steel structure inside the tank does not have the reversibility of secondary low temperature conditions. Therefore, it is self-evident that the external tank of low-temperature prestressed concrete and the internal tank of steel structure contain large LNG tanks with high construction technology requirements.

【关键词】低温储罐; 裂缝控制; 大体积混凝土; 施工缝; 网片

【Keywords】low temperature storage tank; crack control; mass concrete; construction joint; mesh 【DOI】10.36012/etr.v2i3.1390

\section{1 引言}

低温预应力混凝土 LNG 外罐储罐作为重要支撑和保护 结构, 针对外罐混凝土结构易出现的质量通病控制与消除, 相 关人员需要对施工每一道工序都精益求精、精雕细珧,使 LNG 外罐主体工程不仅在建设期间更加优质,也为长期投入 生产运行期发挥更加安全、高效、经济效益作用, 这是相关人 员不断探索的方向和动力源泉。

\section{2 大型 LNG 外罐结构混凝土特点}

外罐主体结构混凝土等级为 C50R28dF200 低温预应力 混凝土,设计混凝土不仅要符合预应力混凝土要求, 而且强度 等级和抗冻融等级高, 结构设计无后浇带和温度变形缝、沉降 缝等设置, 为大形整体式高全构筑物。以 20 万 $\mathrm{m}^{3}$ 储罐为例, 承台混凝土厚度达 $1.2 \sim 1.4 \mathrm{~m}$, 直径达 $90 \mathrm{~m}$ ，浇筑方量约 $9000 \mathrm{~m}^{3}$; 罐壁厚度 $0.8 \sim 1.1 \mathrm{~m}$, 建筑高度达 $45 \mathrm{~m}, 4 \sim 6$ 个附着式
扶壁柱针固肋, 浇筑方量 $12000 \mathrm{~m}^{3}$; 穹顶厚度 $0.5 \sim 1.1 \mathrm{~m}$, 建筑 高度达 $58 \mathrm{~m}$, 浇筑方量 $4500 \mathrm{~m}^{3}$ 。低温混凝土施工配比优化设 计, 合理划分施工段和设置施工缝, 以及减少大体积混凝土有 害裂缝, 减少罐壁墙体有害裂缝、变截面结构, 长期以来是外 罐混凝土结构设计、施工的研究难点和重点 ${ }^{[1]}$ 。

\section{LNG 外罐施工的特点}

\section{1 低温混凝土施工配合比设计}

低温混凝土施工配合比设计时, 不仅需要满足现有国家 和行业规范、设计规格书要求, 而且选取原材料一定充分考虑 满足单个材料技术指标要求的粗骨料、细骨料与胶凝材料之 间的匹配性, 与外加剂、水的兼容性, 以及季度温湿度环境相 关性, 做好原料存储和拌和条件确认。每次施工前都应做好技 术判定, 实时微调, 以改善和提高混凝土拌和的工作性能。在 胶凝材料中掺和硅粉等细颗粒材料时, 虽有助于提高混凝土 的密实性、耐久性和抗腐蚀性, 但掺和量控制不精湛, 也导致 
早期混凝土水化热过高或促进水泥水化过快, 易导致混凝土 结构出现裂纹、裂缝 ${ }^{[2]}$ 。混凝土的水化热是由于水泥水化产生 的, 内外温差过高, 所以在大体积混凝土配合比设计时, 在提 高混凝土性能的同时, 充分利用混凝土的后期强度, 采用 $60 \mathrm{~d}$ 强度设计配合比是有利的。

\section{2 根据设计图纸尺寸和施工工艺特点, 合理划 分施工段和设置施工缝}

在筏板承台基础钢筋安装数量大、高度较高, 对上层钢筋 的支撑一直是设计和施工考虑的重点, 结合现场承台外侧区 域钢筋间距小、直径大的分部规律, 使用焊接成型钢筋骨架支 撑体系支撑上部钢筋, 代替马登筋的传统支撑方式, 提高承台 上层钢筋整体稳定性能和受力性能, 不仅施工期间作业人员 安全, 而且布置均匀, 施工更方便, 速度更快。如在钢筋的骨架 上焊接 $\mathrm{T}$ 形钢筋支架, 在支架上面放置方钢, $40 \times 80$ 方钢上表 面标高控制为 \pm 0.000 , 间距 $3 \mathrm{~m}$ 布置, 同时方便对承台浇筑段 进行浇筑分区。分区域浇筑过程中, 用 $5 \mathrm{~m}$ 长铝质刮尺刮平混 凝土, 再使用振捣梁对上表面进行振捣, 保证混凝土表面平整 光滑, 方便下阶段混凝土表面收光, 使混凝土表面平整符合设 计要求 ${ }^{[3]}$ 。

因筏板承台基础较厚, 具有自重大、施工荷载大特点, 为 了减小承台底面模板排架支撑体系的变形量, 选用 $10^{\#}$ 工字 钢作为排架体系的主梁。相对于传统的 $10^{\#}$ 木方, $10^{\#}$ 工字钢 不仅可以重复利用, 而且安装程序简单, 拆装方便, 既节省了 材料, 缩短施工工期, 又可以提高排架体系稳定性和强度、刚 度, 确保拆模后的混凝土表面观感质量。

罐壁墙体混凝土施工, 在 DOKA 系统 (钢木组合大模板 提升系统)运用多年的情况, 每一层墙体施工高度基本是固定 的,一般高度 $3.6 \mathrm{~m}$ 为标准层。但第一层墙体是施工的关键, 因 该层是与基础承台间相连接, 设计为硬约束, 剪应力为最大, 除设计高出基础承台面 300mm 施工导墙外, 还应考虑第一层 板墙混凝土浇筑完成后, 控制拆模时间不宜过早,一般控制在 $14 \mathrm{~d}$ 以上为宜。且在第一层墙体内外侧主钢筋网片外增设满 布一层或两层抗裂钢筋网片, 保护层控制在 $30 \mathrm{~mm}$ 为宜, 以提 高混凝土抗拉性能, 减少该层混凝土墙体裂纹、裂缝数量, 避 免出现有害裂缝。罐壁为圆柱形墙体, 浇筑混凝土泵车不仅要 满足浇筑高度和覆盖半径要求, 而且数量宜采用四台一备用, 两辆一组, 在平面上成对称方式布料, 每层浇筑高度控制在不 大于 $1.2 \mathrm{~m}$, 采用分层大斜面浇筑法, 较少混凝土分层不均匀 导致“冷缝”或“水缝”出现。

罐壁墙体钢筋绑扎, 一般采用在地面绑扎成水平宽度 $12 \mathrm{~m}$ 长, 高度 9 11m的网片, 塔吊吊装至施工作业面施工方
法, 以节约工序交接时间和节省钢筋搭接数量。因此, 在网片 设计时, 必须选择起重量、起重半径相匹配的塔吊形号; 对高 大网片吊装前应检查吊点加固、网片附加钢筋加固、吊装扁担 等起吊措施确认; 网片在作业面就位时, 必须同上一道工序安 装完成的 $16^{\#}$ 工字钢可拆式劲性柱连接牢固, 并结合抗风拉 带绑扎牢固, 方可卸下塔吊钩, 以确保施工安全。

DOKA 模板体系组装和提升是储罐罐壁施工的重要组成 部分。自公司采用 DOKA 模板体系以来, 一直致力于 DOKA 模板体系的优化与创新, 通过对施工作业上中下三层平台采 用钢跳板代替木跳板, 极大地减少了 DOKA 模板的整体重 量, 增加了平台板的刚度, 方便了吊装策划。由于钢结构的应 用, 并减少木结构的使用, 避免了木结构吸水膨胀变形的问 题, 并增加了跳板的周转率, 极大地降低成本费用。另外, 钢结 构定制加工, 拆装方便, 简化了 DOKA 模板的拆装程序。

储罐穹顶浇注具有高度高、坡度大、面积大的特点。在施 工机械方面可以采取安装布料机进行布料; 也可以采用 $65 \mathrm{~m}$ 及以上泵车, 两台塔吊辅助的形式。因穹顶为变截面半球面结 构, 因此采用分段分圈浇筑方式, 每一圈可以采用分上下两层 或单层浇筑, 以缩短罐内保压时间和表面收光、减少不规则裂 纹、裂缝为宗旨。在穹顶施工前, 其他专业辅助配合尤为重要, 如内罐的保压、环梁预应力的张力和注浆等工作条件必须逐 一确认, 以确保穹顶施工期间安全。相邻圈间坚向施工缝采用 安装免拆收口网, 以提高不同龄期混凝土的抗拉性能, 在工艺 间隙期达到设计要求后, 先清理收口网表面松散的结浆, 用清 水清理干净, 并保持湿润状态, 方可浇筑。

\subsection{LNG 外罐变截面}

变截面一般为主体结构薄弱或补强结构部位, 必须合理 留设施工缝位置, 严格执行相关规范和设计要求, 不可遗漏附 加补强钢筋, 模板安装尺寸、位置需精确, 浇筑混凝土需注意 安全, 拆模必须符合条件允许,才能拆除。

\section{4 结语}

为打造质量过硬企业品牌效应, 提供一流施工水平服务, 论文认真总结了近几年施工经验和工艺技术创新点, 希望能 够更好地指导现场施工并为设计单位提供合理的优化建议, 为节能、节材等环保尽一份力量。

\section{参考文献}

[1]GB 51081一2015 低温环境混凝土应用技术规范[S].

[2]GB 50496-2018 大体积混凝土施工标准 [S].

[3]上海电建. 液化天然气 $(\mathrm{LNG})$ 储罐土建工程施工 $[\mathrm{M}]$. 北京: 中 国电力出版社, 2019 . 